\title{
The effect of radiation exposure on multidrug resistance: in vitro and in vivo studies using non-small lung cancer cells
}

\author{
Shohei Kanno*, Keita Utsunomiya, Yumiko Kono, Noboru Tanigawa and Satoshi Sawada
}

\begin{abstract}
Background: Technetium-99m methoxyisobutylisonitrile (TC MIBI) is a substrate with the same uptake kinetics as doxorubicin. Multidrug resistance (MDR) is a mechanism that impedes chemotherapy of non-small cell lung cancer (NSCLC). We examined the effect of radiation exposure on MDR in NSCLC and the synergy between an MDR modulator, GG918, and radiation, using ${ }^{99 \mathrm{~m}} \mathrm{TC}$ MIBI in vitro and doxorubicin in vivo.

Methods: In vitro NSCLC cells (H1299) were exposed to radiation (3-, 6-, and 9-Gy-irradiated groups) alongside a not-irradiated (0 Gy) group. Technetium-99 metastable methoxyisobutylisonitrile $\left({ }^{99 \mathrm{~m}} \mathrm{TC} \mathrm{MIBI}\right)$ was administered to cell suspensions at $48 \mathrm{~h}$ after irradiation. Cell radioactivity was measured, and $C_{\text {in }} / C_{\text {out }}$ ratios were calculated and compared. NSCLC cells were also subcutaneously transplanted into the left thigh of nude mice, which were subsequently raised for 2 weeks. Two groups of mice were used: mice exposed to irradiation (9-Gy-irradiated) and those that were not (not-irradiated). Doxorubicin was administered through the caudal vein at $48 \mathrm{~h}$ after the irradiation. Using an in vivo imaging system, intratumoural photon counts were measured. To determine the synergy between the MDR modulator and 3- or 6-Gy irradiation, the final GG918 concentration was determined: $0.1 \mu \mathrm{M}(\mathrm{N}-\mathrm{H}, 3-\mathrm{H}$, and 6-H groups), $0.001 \mu \mathrm{M}$ ( $\mathrm{N}-\mathrm{L}, 3-\mathrm{L}$, and 6-L groups), and $0 \mu \mathrm{M}$ (N-0, 3-0, and 6-0 groups). $\mathrm{C}_{\text {in }} / \mathrm{C}_{\text {out }}$ ratios were calculated and compared among the groups.

Results: $C_{\text {in }} / C_{\text {out }}$ after 6- or 9-Gy irradiation was significantly higher than that of the not-irradiated group (0 Gy). In vivo, fluorescence photon counts were significantly higher in the tumours of 9-Gy-irradiated mice, up to 270 min after administration of doxorubicin, as compared to the not-irradiated mice. The $C_{\text {in }} / C_{\text {out }}$ ratio in the $\mathrm{N}-\mathrm{H}$, $3-\mathrm{H}$, and $6-\mathrm{H}$ groups was significantly higher than that in the $\mathrm{N}-0,3-0$, and $6-0$ groups. There was no significant difference between $C_{\text {in }} / C_{\text {out }}$ in the $\mathrm{N}-\mathrm{L}$ group and that of the $\mathrm{N}-0$ group. However, the $C_{\text {in }} / C_{\text {out }}$ ratio in the 3-L and 6-L groups was significantly higher than that in the 3-0 and 6-0 groups.
\end{abstract}

Conclusions: Irradiation decreased MDR in NSCLC cells. In combination with a low-dose MDR modulator, GG918, MDR transport function was synergistically reduced $48 \mathrm{~h}$ post-irradiation.

Keywords: ${ }^{99 \mathrm{~m}} \mathrm{TC}$ MIBI; Doxorubicin; Irradiation; MDR; Non-small cell lung cancer

\section{Background}

Non-small cell lung cancer (NSCLC) accounts for more than $80 \%$ of diagnosed lung cancer cases and is often detected at an advanced stage, rendering it extremely difficult to treat with current therapeutic regimes. Lung cancer that is detected in the advanced stage may be treated with molecular-targeted drugs; however, it is commonly treated

\footnotetext{
* Correspondence: kanno@ka2.so-net.ne.jp

Department of Radiology, Kansai Medical University, 2-5-1 Shinmachi, Hirakata 573-1010, Osaka, Japan
}

with chemoradiotherapy [1]. For chemotherapy, the current practice is to deliver several anticancer drugs with different mechanisms of action, thereby reducing the dose of each drug required, thus, decreasing the occurrence of side effects, as well as benefitting from synergistic tumour reduction effects. Thus, combination therapy is commonly used as a treatment regimen for lung cancer.

On the other hand, radiotherapy depends on the sensitivity of specific tumour cells to radiation. The effectiveness of hyperfractionated radiation therapy, i.e., irradiation over 
optimal intervals, targeting the most sensitive stages of the tumour cell cycle, has also been investigated. The goal of established chemoradiotherapy is to achieve tumour volume reduction, whereas novel combinations of chemotherapy and radiotherapy aim to reduce both tumour volume as well as the occurrence of side effects. However, combination therapies are often discontinued because of the side effects of both irradiation and anticancer drugs.

Furthermore, there is a growing concern that treatment efficacy may not be sufficient because of multidrug resistance (MDR) [2]. The overexpression of P-glycoprotein (Pgp) and breast cancer-resistant protein (BCRP) in the membranes of tumour cells plays a major role in the development of MDR [3,4]. Cancer cells bearing the MDR phenotype are capable of eliminating anticancer drugs, such as cisplatin or doxorubicin, by using Pgp and BCRP as an efflux channel protein, thereby diminishing their chemotherapeutic actions [4].

${ }^{99 \mathrm{~m}}$ Tc MIBI, used for myocardial perfusion scintigraphy and imaging of the parathyroid gland, is a substrate of Pgp and is known to have similar tumour cell kinetics to cisplatin and doxorubicin [5]. In addition, MDR modulators (e.g., verapamil, GG918, PSC833, and cyclosporin A) reduce the transporter function of Pgp and BCRP [6,7]. These modulators bind to Pgp and BCRP, thereby preventing these membrane-bound protein channels from transporting anticancer drugs out of tumour cells. However, to achieve this effect, a high dose of such modulators must be administered $[8,9]$. Consequently, these modulators have not been used in combination with any chemoradiotherapeutic or chemotherapeutic regimen, due to concerns regarding their toxicity.

In this study, NSCLC cells (in vitro) and tumours (in vivo) with an MDR phenotype were exposed to varying doses of radiation, as well as ${ }^{99 \mathrm{~m}} \mathrm{Tc}$ MIBI and doxorubicin, respectively, to investigate the effect of radiation on MDR and MDR modulators.

\section{Methods}

\section{Ethical consideration}

In this study, the institutional and national guide for the care and use of laboratory animals was followed and the protocols used were approved by the Institutional Review Board of Kansai Medical University.

\section{Reagents}

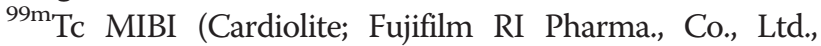
Tokyo, Japan) and doxorubicin (Adriamycin; Kyowa Hakko Kirin Co., Ltd., Tokyo, Japan) were used as tracers. A stock solution of ${ }^{99 \mathrm{~m}}$ Tc MIBI was prepared by mixing $10 \mathrm{MBq}$ of ${ }^{99 \mathrm{~m}}$ Tc MIBI with $2 \mathrm{~mL}$ of saline solution; this solution was then used in the in vitro and in vivo experiments [10,11]. A stock solution of doxorubicin was prepared by mixing $1 \mathrm{mg}$ of doxorubicin with $1 \mathrm{~mL}$ of saline solution. This solution was then used in the in vivo experiment. A stock solution of MDR modulator was prepared from an acridone carboxamide derivative, GG918, (N-\{4-(2-(1,2,3,4-tetrahydro-6,7-dimethoxy-2-isoquinolinyl)-ethyl)-phenyl\}-9,10-dihydro-5-methoxy-9-oxo-4acridine carboxamide; Elacridar; MedChem Express, LLC, Monmouth Junction, NJ, USA) [7,12].

\section{Cell culture and xenografts}

In vivo and in vitro experiments were conducted using NSCLC cells (H1299), transfected with a wild-type P53encoding gene, which was supplied by Hideki Matsumoto, Ph.D., Oncology, Biomedical Imaging Research Centre, Fukui University, Japan [13]. ICR nude mice (Crlj: CD1Foxn1nu) were used for xenografting (Charles River Laboratories, Wilmington, MA, USA) [14].

For the in vitro study, H1299 cells were cultured as monolayers in Dulbecco's alpha-MEM medium (DMEM; Sigma-Aldrich, St. Louis, MO, USA) supplemented with $10 \%(v / v)$ foetal bovine serum (EquitechBio, Kerrville, TX, USA), $50 \mu \mathrm{g} / \mathrm{mL}$ streptomycin, and $200 \mu \mathrm{g} / \mathrm{mL}$ geneticin and were incubated at $37^{\circ} \mathrm{C}$ in $95 \%$ air and $5 \% \mathrm{CO}_{2}$. Prior to culturing, the cells were subjected to 3-, 6-, and 9-Gy (irradiated groups) gamma irradiation (Gammacell 40 Exactor, Nordion International, Ottawa, Canada). Cells from the irradiated groups and the not-irradiated group were cultured for $48 \mathrm{~h}$ as previously described. H1299 cells were trypsinized and centrifuged, and each cell suspension was diluted to a density of 0.5 to $1.0 \times 10^{6}$ cells/mL [10,11].

For the in vivo study, H1299 cells were cultured as previously described, trypsinized, and then centrifuged four times with Dulbecco's phosphate-buffered saline (D-PBS; Gibco; Invitrogen Co., Ltd, Carlsbad, CA, USA) at $4^{\circ} \mathrm{C}$, after which cells were resuspended in D-PBS. We transplanted $5.0 \times 10^{7}$ cells into the left thighs of mice, which were then raised for 2 weeks to allow tumour formation [12,14,15]. After 2 weeks, the tumour volume $\left(\mathrm{mm}^{3}\right)$ was calculated; tumours $\geq 20 \mathrm{~mm}^{3}$ were used for further study. Xenografts were subjected to 9-Gy gamma irradiation (Gammacell 40 Exactor, Nordion International, Ottawa, Canada), incubated for $48 \mathrm{~h}$, and then used for experimentation.

\section{Expression of transporters in $\mathrm{H} 1299$ cells}

H1299 cells were smeared onto silane-coated slides (No. 5136, MUTO, Co.. Ltd., Tokyo, Japan) and fixed in 100\% ethanol. The cells were incubated in $0.3 \% \mathrm{H}_{2} \mathrm{O}_{2}$ in $0.05 \mathrm{M}$ D-PBS for $15 \mathrm{~min}$ at room temperature and then washed three times with $0.05 \mathrm{M} \mathrm{PBS}$ for $3 \mathrm{~min}$. Afterwards, the cells were blocked with $5 \%$ skim milk $(v / v)$ and $0.15 \%$ $\mathrm{H}_{2} \mathrm{O}_{2}(v / v)$ in de-ionized water for $20 \mathrm{~min}$ at room temperature. Primary antibodies against Pgp and BCRP were then added and allowed to react with the cells 
overnight at room temperature. Transporters were detected using a 1/500 dilution of anti-BCRP/ABCG2 antibody (ab72788, Abcam, Co., Ltd., Cambridge, MA, USA) or antiPgp monoclonal antibody (4E3.16, \#517308, Calbiochem, Co., Ltd., San Diego, CA, USA). Isotype control was conducted using mouse IgG1 (ICIGG1; ab91353, Abcam, Co., Ltd., Cambridge, MA, USA) and mouse control IgG2a [MOPC-173] - ChIP Grade (ab18413).

After washing with $0.05 \mathrm{M}$ PBS, the cells were incubated in $0.05 \mathrm{M}$ D-PBS containing peroxidase-labelled polymer conjugated to goat anti-mouse immunoglobulin for $30 \mathrm{~min}$. After washing with $0.05 \mathrm{M}$ D-PBS, the slides were stained with 3-3'-diaminobenzidine-4 $\mathrm{HCl}$ (DAB) for $1 \mathrm{~min}$. Finally, the slides were washed in 0.05 M PBS and stained with $50 \%$ Mayer's haematoxylin on the cover slide for 1 min [15].

To assess the quality of Pgp and BCRP expression, Allred scores were used; the proportion score (PS); the percentage of cells that were stained by immunocytochemistry (on a scale of 0 to 5) and the intensity score (IS); the intensity of the staining (on a scale of 0 to 3), for a total possible score of 8 . Total scores were compared between the 9-Gy-irradiated and not-irradiated tumour cells [16].

\section{Cellular accumulation of ${ }^{99 \mathrm{~m}} \mathrm{Tc}$ MIBI}

To determine cellular transport activity, cell suspensions $(7.0 \mathrm{~mL})$ were thoroughly mixed and incubated in a $37^{\circ} \mathrm{C}$ water bath. Approximately $100 \mu \mathrm{L}$ of ${ }^{99 \mathrm{~m}} \mathrm{Tc}$ MIBI was then added to the cell suspensions. To evaluate intracellular accumulation, $300 \mu \mathrm{L}$ aliquots were collected in duplicate $1,15,30,45$, and 60 min after ${ }^{99} \mathrm{~m}$ Tc MIBI administration. The aliquots were transferred to $1.5-\mathrm{mL}$ microcentrifuge tubes containing $1.0 \mathrm{~mL}$ of ice-cold saline and centrifuged at 14,000 rpm for $2 \mathrm{~min}$; the supernatants were removed, and the cells washed gently with $0.5 \mathrm{~mL}$ of ice-cold saline solution. Radioactivity in the cell pellets was measured at 90 to $190 \mathrm{keV}$ using a gamma-counter (WIZARD ${ }^{\mathrm{m}}$ 3" Model 1480 Automatic Gamma Counter, PerkinElmer Life Sciences, Co., Ltd., Waltham, MA, USA). The accumulation ratio $\left(C_{\text {in }} / C_{\text {out }}\right)$ was calculated as the ratio of intracellular to extracellular radioactivity in an equal volume of supernatant medium, using an independent measurement of cell volume as described previously [11]. The time course of ${ }^{99 \mathrm{~m}}$ Tc MIBI accumulation was measured in the not-irradiated group and in the 3-, 6-, and 9-Gy-irradiated groups $[10,11]$.

\section{Accumulation of doxorubicin in tumours}

Doxorubicin (stock solution, $100 \mu \mathrm{L}$ ) was administered via the caudal vein to the not-irradiated mice and the 9-Gy-irradiated mice at $48 \mathrm{~h}$ after irradiation for in vivo fluorescence imaging [17]. Fluorescence (photons $" \mathrm{~s}^{-1 . "} \mathrm{~cm}^{-2}$ ) was measured, to evaluate the accumulation of doxorubicin
(Figure 1), in the xenografted tumour thigh region and in the bilaterally symmetrical control thigh region using an in vivo imaging system (IVIS 200, Caliper Life Science Inc., Hopkinton, MA, USA) equipped with air-cooled argon lasers (emission at $488 \mathrm{~nm}$ ) and a $575-\mathrm{nm}$ band pass filter $[11,15]$. Changes in doxorubicin accumulation in the ROIs were detected by fluorescence imaging over time. Washout rate was calculated using the following equation:

Doxorubicin washout rate $(\%)=\{$ (Fluorescence in the tumour at $10 \mathrm{~min}$ after doxorubicin administration-Fluorescence at 60 ,

120 , or $270 \mathrm{~min}$ after doxorubicin administration)/Fluorescence at $10 \mathrm{~min}$ after doxorubicin administration $\} \times 100$.

\section{Effects of GG918 on ${ }^{99 m} \mathrm{Tc}$ MIBI accumulation in cells after irradiation}

H1299 cells were subjected to 3- and 6-Gy gamma irradiation. Irradiated cells and not-irradiated cells were separately cultured in tissue culture flasks. H1299 cells were trypsinized and centrifuged to prepare $7 \mathrm{~mL}$ of single-cell suspensions in fresh media with a density of 0.5 to $1.0 \times 10^{6}$ cells $/ \mathrm{mL}$. GG918 was added to a final concentration of $0,0.001$, and $0.1 \mu \mathrm{M}$ to the irradiated and not-irradiated cell suspensions at $5 \mathrm{~min}$ before addition of ${ }^{99 \mathrm{~m}}$ Tc MIBI. In the not-irradiated group, the cell suspensions to which $0,0.001$, and $0.1 \mu \mathrm{M}$ of GG918 were added were defined as the $\mathrm{N}-0$ group, the $\mathrm{N}-\mathrm{L}$ group, and the

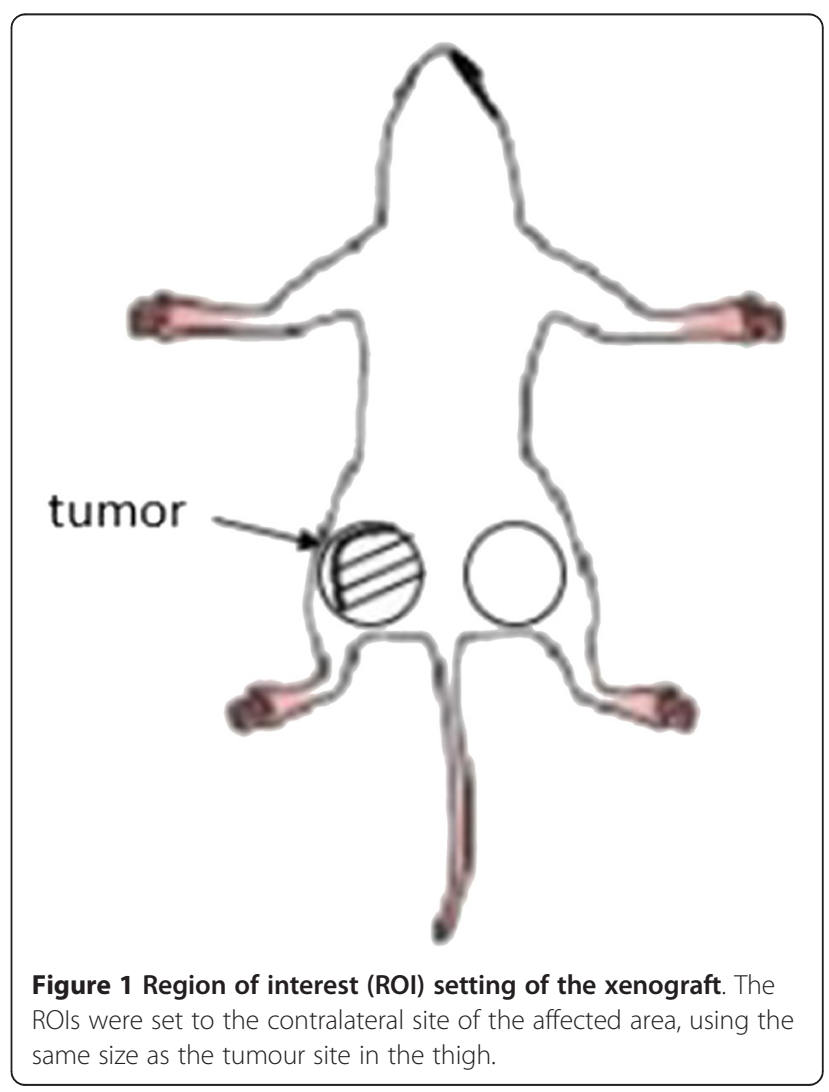




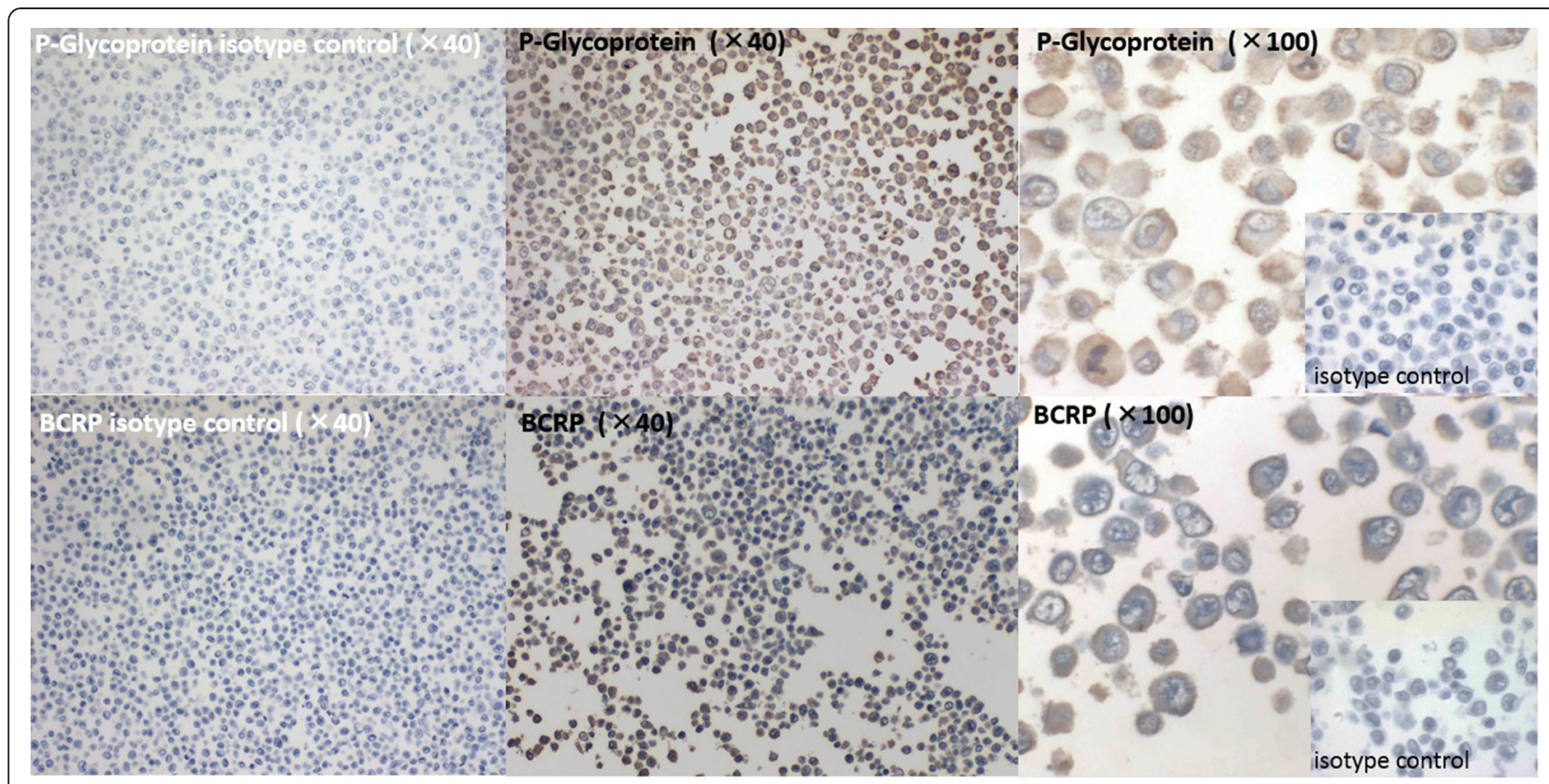

Figure 2 The immunocytochemistrical expression of Pgp and BCRP. The immunocytochemistrical expression of Pgp and BCRP was positive, the proportion score (PS) 5/5 + the intensity score (IS) $3 / 3=$ total score $8 / 8$, localizing these proteins to the cell membrane of the not-irradiated tumour cells.

$\mathrm{N}-\mathrm{H}$ group, respectively. In the 3- or 6-Gy-irradiated groups, the cells to which $0,0.001$, and $0.1 \mu \mathrm{M}$ of GG918 were added were defined as the 3-0 group or 6-0 group, the 3-L group or 6-L group, and the 3-H group or 6-H group, respectively.
Radioactivity was measured using a gamma counter $30 \mathrm{~min}$ after the administration of ${ }^{99 \mathrm{~m}} \mathrm{Tc} \mathrm{MIBI}$, and the ${ }^{99 \mathrm{~m}}$ Tc MIBI cellular accumulation ratio $\left(C_{\mathrm{in}} / C_{\text {out }}\right)$ was calculated. The accumulation of ${ }^{99 \mathrm{~m}}$ Tc MIBI was compared between the $\mathrm{N}-\mathrm{H}, \mathrm{N}-\mathrm{L}$, and $\mathrm{N}-0$ groups and both

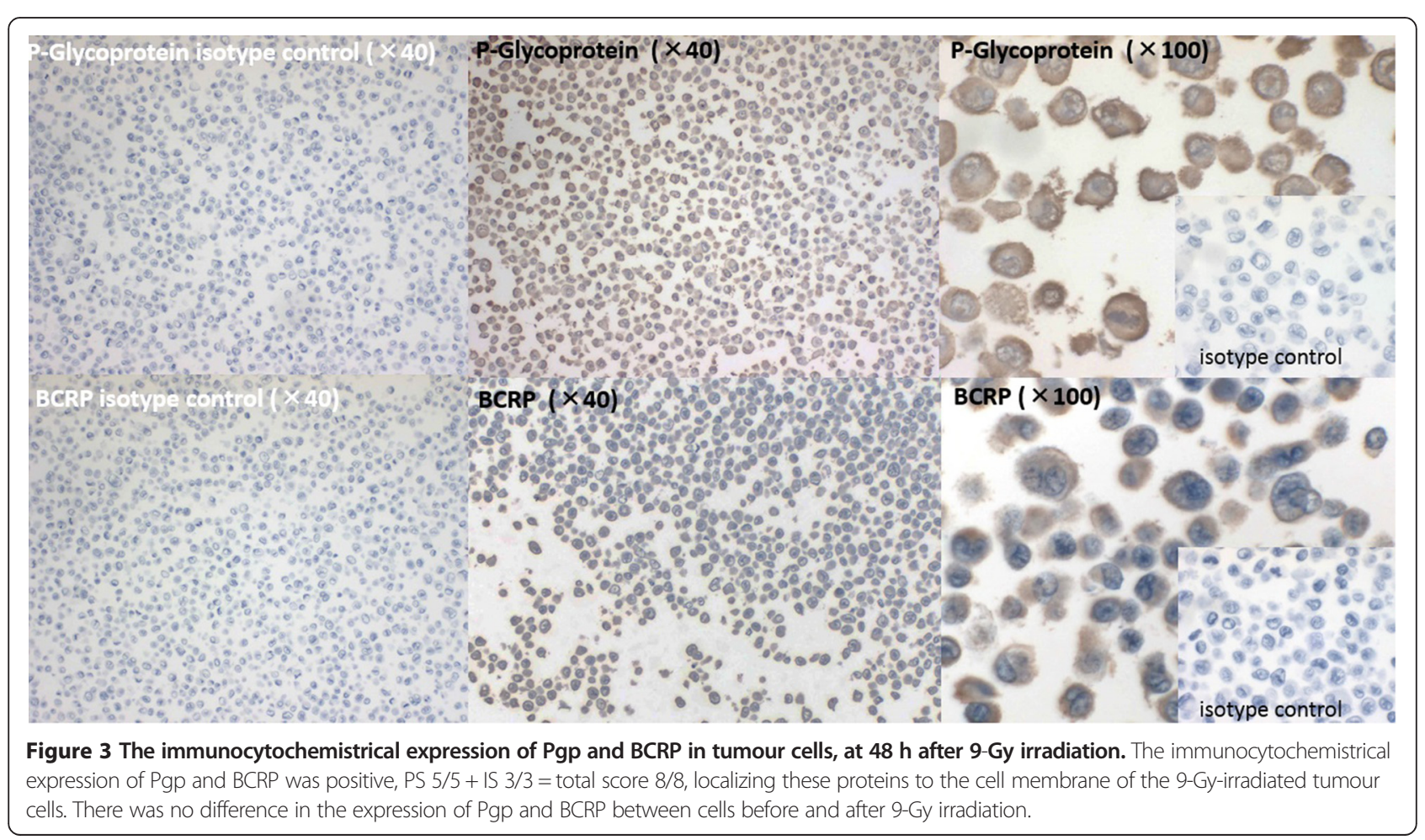


the $3-\mathrm{H}, 3-\mathrm{L}$, and $3-0$ groups and the $6-\mathrm{H}, 6-\mathrm{L}$, and 6-0 groups.

\section{Statistical analysis}

The samples used in the in vitro experiments were measured in duplicate. The data were expressed as the mean \pm standard error (SE). The Kruskal-Wallis test and a post hoc multiple comparison test were conducted using Fisher's protected least significant difference (PLSD) test. A $P$ value less than 0.05 was considered statistically significant.

\section{Results}

\section{Characterization of transporters in $\mathrm{H} 1299$ cells}

Immunodetection of Pgp and BCRP was positive, with these proteins localized in the membranes of H1299 cells (Figures 2 and 3). In the not-irradiated cells shown in Figure 2, the expression of Pgp and BCRP were as follows: PS $5+$ IS $3=8$. There was no change after 9-Gy irradiation, followed by $48 \mathrm{~h}$ of culturing, as shown for the cells in Figure 3, with both Pgp and BCRP being PS $5+$ IS $3=8$.

\section{Cellular accumulation of ${ }^{99 \mathrm{~m}} \mathrm{Tc}$ MIBI after irradiation}

The cellular accumulation of ${ }^{99 \mathrm{~m}} \mathrm{Tc}$ MIBI is shown in Figure $4 . C_{\text {in }} / C_{\text {out }}$ increased after approximately $30 \mathrm{~min}$. $C_{\text {in }} / C_{\text {out }}$ in all groups reached a plateau within $60 \mathrm{~min}$. $C_{\text {in }} / C_{\text {out }}$ in the 6-Gy-irradiated and 9-Gy-irradiated groups was higher than that in the 3-Gy-irradiated group and the not-irradiated group $(P<0.05)$. There was no significant difference observed between the 3-Gy-irradiated group and the not-irradiated group.

\section{Doxorubicin accumulation in tumours after irradiation}

Figure 5 represents a fluorescence image of a xenograft. The tumour site of the 9-Gy-irradiated mouse exhibited fluorescence, indicating an accumulation of doxorubicin, whereas the tumour site of the not-irradiated mouse did not exhibit significant fluorescence, indicating little or no doxorubicin accumulation.

Figure 6 shows the fluorescence photon count as a function of time. Compared to the tumour site of the notirradiated mouse, the tumour site of the 9-Gy-irradiated mouse showed significantly higher accumulation, with

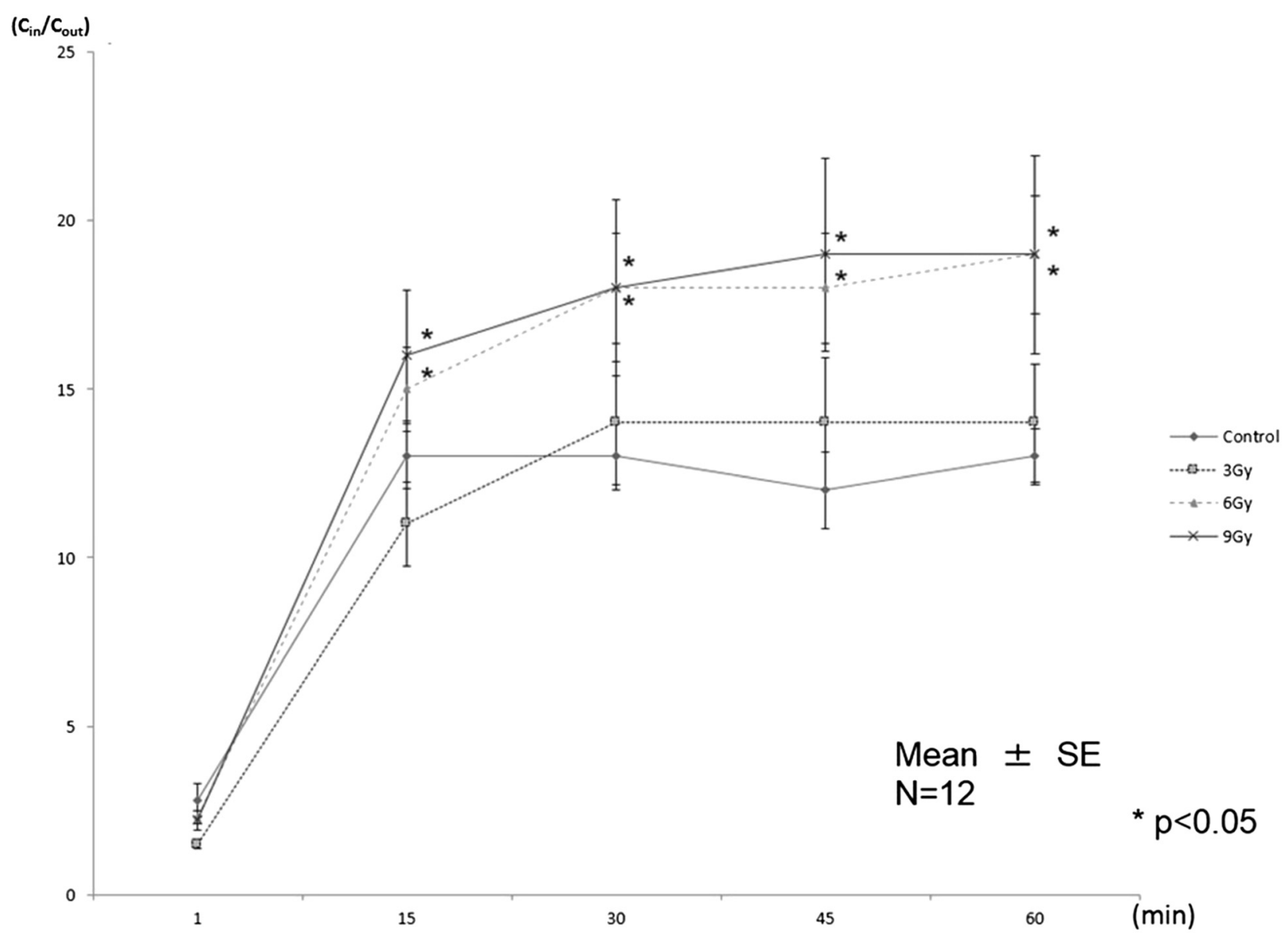

Figure $4^{{ }^{99 m}}$ Tc MIBI accumulation study. Compared to the not-irradiated group, the cellular uptake of ${ }^{99 \mathrm{~m}} \mathrm{Tc}$ MIBI increased statistically significantly in the 6-Gy group and the 9-Gy group. 


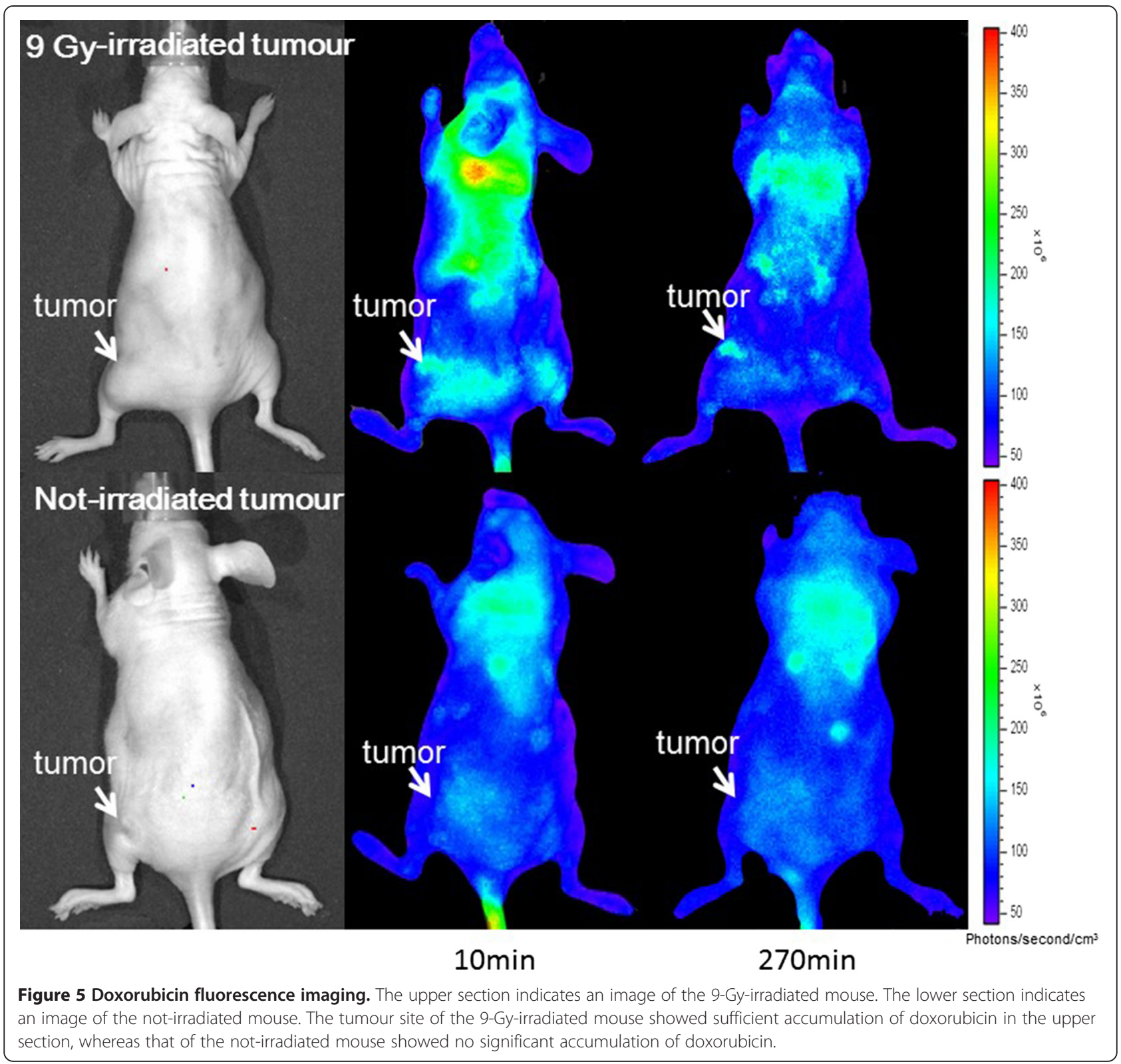

rapid uptake over the initial 10 min after doxorubicin administration.

The washout rate for the tumour site of the 9-Gyirradiated mouse was $4.3 \% \pm 0.5 \%$, whereas that of the tumour site of the not-irradiated mouse was $12.3 \% \pm 2.2 \%$ by $30 \mathrm{~min}$ after doxorubicin administration. Approximately 120 min after doxorubicin administration, approaching the midpoint of photo counting, the washout rate of the tumour site of the 9-Gy-irradiated mouse was 3.4\% $\pm 0.3 \%$, whereas that of the tumour site of the not-irradiated mouse was $23.4 \% \pm 3.5 \%$. At $270 \mathrm{~min}$ after administration, i.e., at the endpoint of photon counting, the washout rate of the tumour site of the 9-Gy-irradiated mouse was $15.0 \% \pm 2.3 \%$, whereas that of the tumour site of the not-irradiated mouse was $45.8 \% \pm 1.8 \%$. Therefore, the washout rate of the tumour site of the 9-Gy-irradiated mouse was significantly lower, over the $270 \mathrm{~min}$ of measurement after administration, compared to that of the not-irradiated mouse, indicating that significantly more doxorubicin remained within the tumour.

\section{Cellular accumulation of ${ }^{99 \mathrm{~m}} \mathrm{Tc}$ MIBI in the presence of} GG918 after irradiation

Figure 7 presents the accumulation of ${ }^{99} \mathrm{~m}$ Tc MIBI in cultured NSCLC cells to which the MDR modulator GG918 had been added. Although the ${ }^{99 \mathrm{~m}}$ Tc MIBI accumulation in the $\mathrm{N}-\mathrm{H}$ group was significantly higher than that in the $\mathrm{N}-0$ and $\mathrm{N}-\mathrm{L}$ groups, no significant differences 


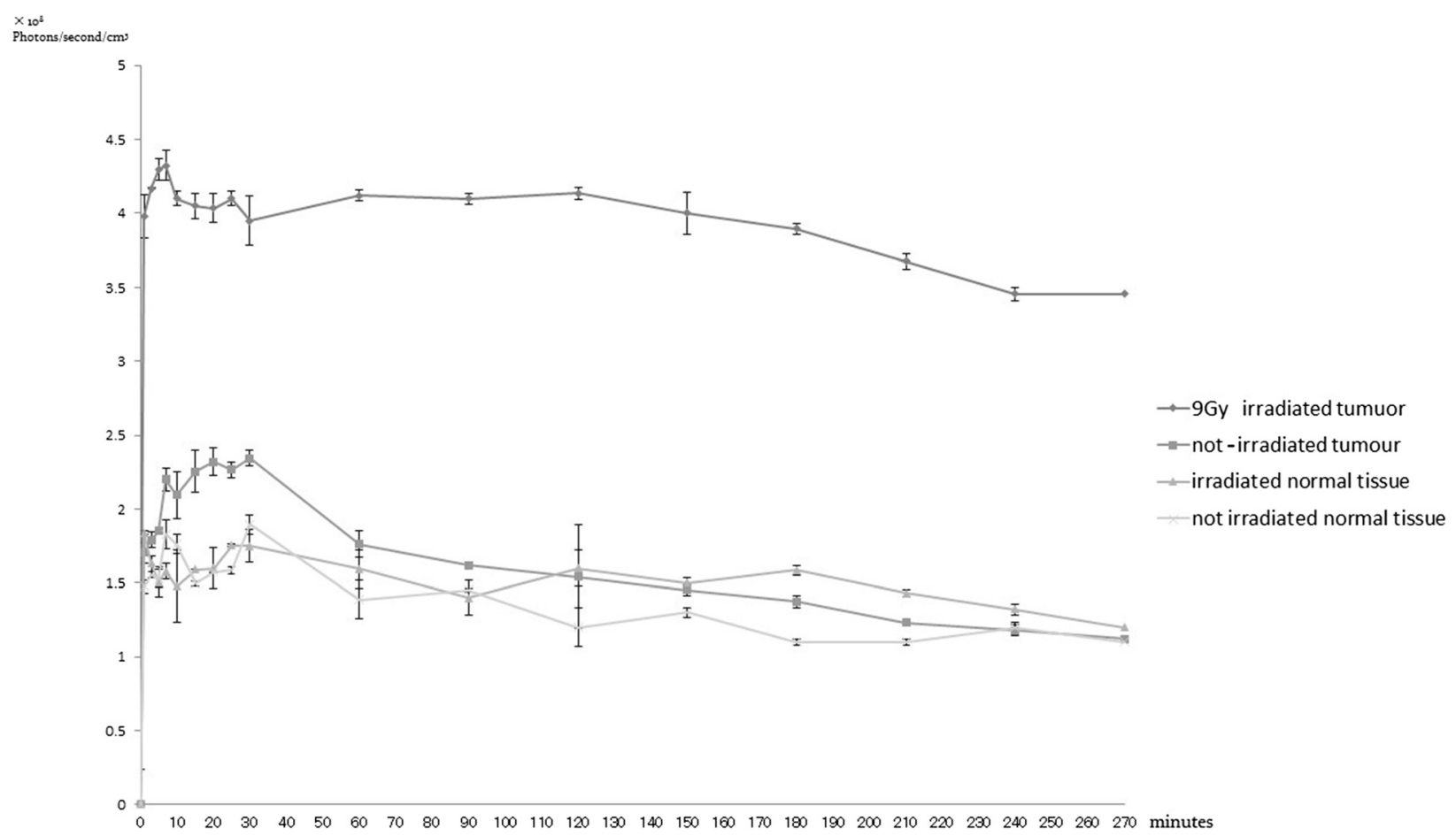

Figure 6 Time-photon curve of doxorubicin in the 9-Gy-irradiated mouse and not-irradiated mouse. The accumulation of doxorubicin in the tumour site of the 9-Gy-irradiated mouse was around 4 to $4.5\left(10^{8}\right.$ photons $\left.\cdot \mathrm{s}^{-1} \cdot \mathrm{cm}^{-3}\right)$ for approximately 120 min after administration and then washed out gradually. On the other hand, the accumulation of doxorubicin in the tumour site of the not-irradiated mouse was around 2 to 2.5 $\left(10^{8}\right.$ photons $\left.\cdot \mathrm{s}^{-1} \cdot \mathrm{cm}^{-3}\right)$ at 30 min after administration, which was significantly lower than that in the 9-Gy-irradiated mouse. The site was subjected to washout at $30 \mathrm{~min}$ after administration, although the degree of washout was significantly greater than that observed in the 9-Gy-irradiated mouse.

in the accumulation between the N-L group and N-0 group were observed. ${ }^{99 \mathrm{~m}} \mathrm{Tc}$ MIBI accumulation in the 3$\mathrm{H}$ group was significantly higher than that in the 3-0 and 3-L groups. ${ }^{99 \mathrm{~m}} \mathrm{Tc}$ MIBI accumulation in the $3-\mathrm{L}$ group was significantly higher than that in the 3-0 group. The 6-0, 6-L, and 6-H groups also showed the same significant tendency as the $3-0,3-\mathrm{L}$, and $3-\mathrm{H}$ groups. ${ }^{99 \mathrm{~m}} \mathrm{Tc}$ MIBI accumulation was enhanced by irradiation, even in the presence of a low dose of GG918.

\section{Discussion}

Pgp and BCRP are known to actively transport anticancer drugs, such as doxorubicin and cisplatin, out of cells; however, their actual mechanism of action remains elusive. This mechanism of active elimination of anticancer drugs is one key factor that gives rise to MDR. Reducing MDR transport function has been an important ongoing challenge in cancer treatment and has thus been extensively investigated $[3,8,9]$. This study revealed enhanced uptake of ${ }^{99 \mathrm{~m}}$ Tc MIBI in NSCLC cells in vitro after 6- and 9-Gy irradiation, and an extended intracellular doxorubicin residence time in in vivo xenografted NSCLC tumours at $48 \mathrm{~h}$ after 9-Gy irradiation, although there was no difference in the expression of Pgp and BCRP between cells before and after 9-Gy irradiation immunocytochemically.
Thereby suggesting that MDR transport function may have been reduced in both in vitro and in vivo experiments. In clinical lung cancer treatment, however, $6 \mathrm{~Gy}$, 9 Gy, or higher doses of irradiation per radiotherapy do not constitute an established treatment method, due to a lack of evidence that reduces tumour volume. However, studies have shown that a reduction in MDR transport function can be achieved using low-dose fractionated radiation therapy (LDFRT) $[18,19]$. A previous study has demonstrated a reduction of MDR transport function in highly radiosensitive oral squamous cell carcinoma cell lines by 48 or $72 \mathrm{~h}$ after irradiation [18]. The administration of chemoradiotherapy, in combination with cisplatin, to NSCLC cells has also resulted in improved therapeutic efficacy of LDFRT, as compared to single-fraction therapy [19]. These reports suggested that the choice of irradiation method (e.g., LDFRT) and the time elapsed after irradiation, rather than the total radiation dose during treatment, may lead to a reduction in MDR transport function. The present study found no significant reduction in MDR transport function at 24 $\mathrm{h}$ after 6- and 9-Gy irradiation; in vitro ${ }^{99 \mathrm{~m}} \mathrm{Tc}$ MIBI accumulation and in vivo doxorubicin uptake in xenografted tumours were both found to be non-significant (data not shown). However, at $48 \mathrm{~h}$ after irradiation, the in vitro accumulation of ${ }^{99 \mathrm{~m}} \mathrm{Tc}$ MIBI and 


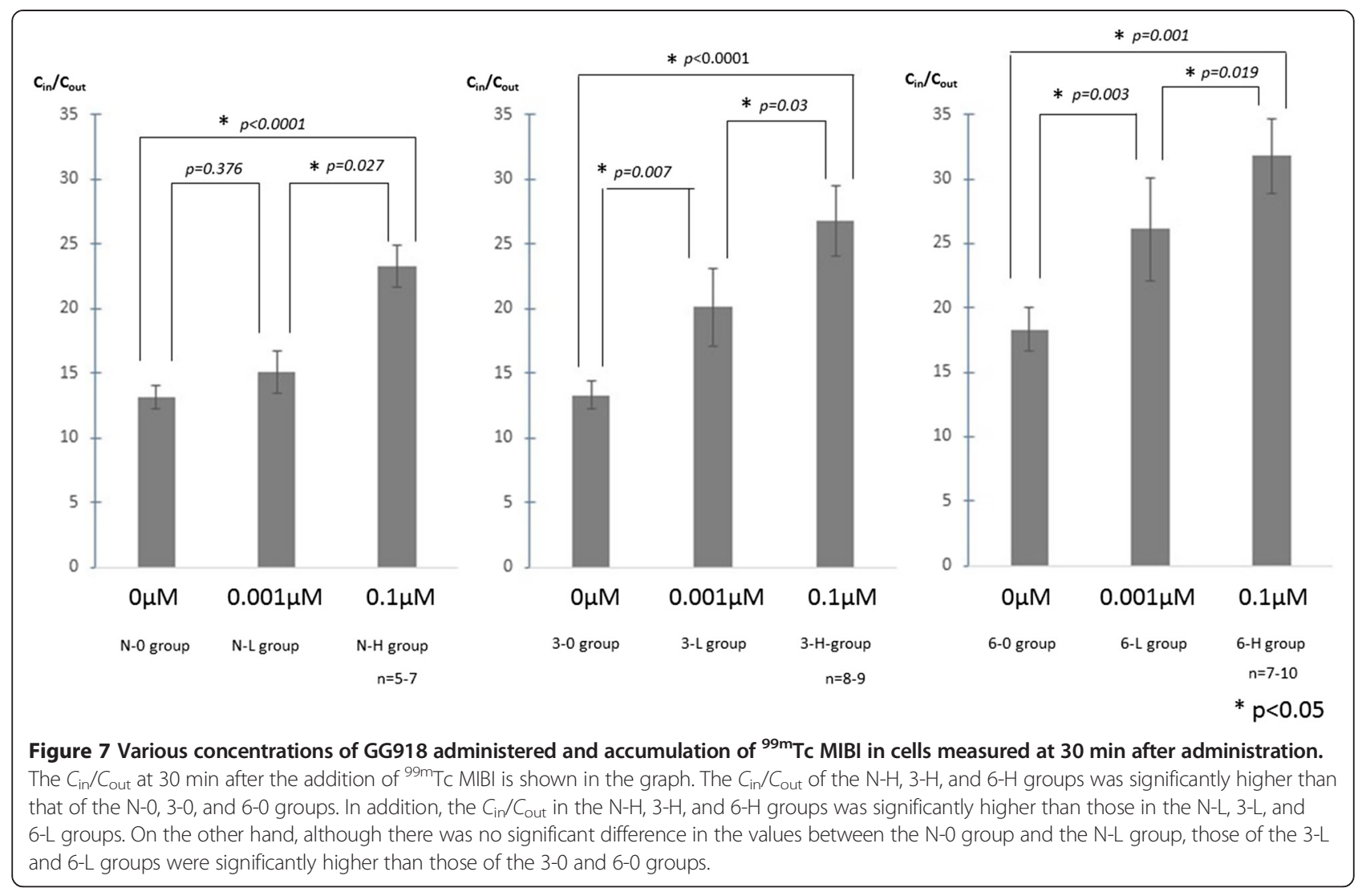

in vivo doxorubicin uptake in the xenografted tumours were both significantly higher than in the not-irradiated groups. These results indicate the potential clinical utility of $6 \mathrm{~Gy}$ or higher doses of single-fraction radiation, which is contrary to the findings of previous studies. Although no report has demonstrated the efficacy of single-fraction radiation, we suggest that one possible reason for this was that the experiments were conducted at less than $48 \mathrm{~h}$ after irradiation.

Pgp and BCRP are localized in the cell membranes of normal cells, such as those of the intestines, lungs, proximal tubules of the kidney, and in capillary endothelial cells of the blood-brain barrier [20]. These transporter proteins are also present in the cells of lung and breast tumours. ${ }^{99 \mathrm{~m}} \mathrm{Tc}$ MIBI has long been used for imaging of myocardial perfusion and parathyroid gland uptake and is known as a substrate of Pgp $[5,10]$. ${ }^{99 \mathrm{~m}}$ Tc MIBI thus exhibits the same kinetics in vivo as doxorubicin and cisplatin. Knowledge of the kinetics of ${ }^{99 \mathrm{~m}} \mathrm{Tc}$ MIBI and doxorubicin may help in planning treatment strategies for cancer. Doxorubicin accumulation in tumour cells can be monitored through fluorescence imaging if the tumour is located on the skin surface. Consequently, it is generally difficult to image doxorubicin as a tracer in humans, and thus, no previous studies have reported this specific imaging approach. Previous studies have shown that ${ }^{99 \mathrm{~m}} \mathrm{Tc}$ MIBI is a suitable radiotracer for imaging and can be used to image tumours [11,12]. Several reports using this approach have noted that the use of high-dose low-efficacy chemotherapy, with the associated serious side effects, can be reduced $[5,21,22]$. In addition, other reports have found that ${ }^{99 \mathrm{~m}}$ Tc MIBI scintigraphy can be used for chemotherapy prognosis in lung cancer, wherein MRP, Pgp, or BCRP are expressed [23,24]. The present study also supported these findings and has shown that ${ }^{99 \mathrm{~m}} \mathrm{Tc}$ MIBI and doxorubicin appear to have similar kinetics.

In this study, we also investigated chemical modulators that reduce MDR transport function as well as the effect of irradiation on MDR transport function. Previous in vitro and in vivo studies have demonstrated that the mechanisms of action of the MDR modulators verapamil, GG918, cyclosporin A, and PSC833 depend largely on the dose of the compounds used $[3,25]$. GG918, a selective MDR modulator of Pgp and BCRP, inhibits the function of these transporters and increases ${ }^{99 \mathrm{~m}}$ Tc MIBI cellular accumulation [10]. A phase I clinical trial using GG918 revealed problems relating to clinical safety and efficacy of this agent [9]. It has also been reported that a concentration of $0.01 \mu \mathrm{M}$ GG918 is ineffective as a modulator and that MDR transport function may be reduced with high doses $(0.1 \mu \mathrm{M}$ or $0.2 \mu \mathrm{M})$; these concentrations, however, 
are toxic to humans $[17,26]$. In the present study, ${ }^{99 \mathrm{~m}} \mathrm{Tc}$ MIBI uptake in in vitro NSCLC cells was high after addition of $0.1 \mu \mathrm{M}$ GG918 in the absence of irradiation. The ${ }^{99 m}$ Tc MIBI uptake in NSCLC cells in vitro did not increase after addition of $0.001 \mu \mathrm{M}$ GG918; however, after 3- or 6-Gy irradiation, the cellular uptake of ${ }^{99 \mathrm{~m}} \mathrm{Tc}$ MIBI significantly increased even after addition of only $0.001 \mu \mathrm{M}$ GG918. These results suggest that the combination of irradiation and a low-dose MDR modulator may synergistically reduce MDR transport function.

\section{Conclusions}

The NSCLC cell line H1299/wtp53 showed a reduction in MDR transport function after irradiation at a dose of 6 Gy or higher. The combination of a low-dose (3 and 6 Gy) irradiation and a low-dose MDR modulator, GG918, resulted in a synergistic effect that reduced MDR transport function. Abbreviations
99mTc MIBI: technetium-99 metastable methoxyisobutylisonitrile; BCRP: breast
cancer-resistant protein; LDFRT: low-dose fractionated radiation therapy;
MDR: multidrug resistance; NSCLC: non-small cell lung cancer; Pgp: P-glycoprotein.

\section{Competing interests}

The authors declare that they have no competing interests.

\section{Authors' contributions}

SK performed the immunocytochemistry. SK, KU, and YK carried out the in vitro study (irradiation in NSCLC using ${ }^{99 \mathrm{~m}} \mathrm{TC}$ MIBI). SK and KU participated in the in vivo study. SK and KU carried out the in vitro study (irradiation and GG918 in NSCLC using ${ }^{99 m} \mathrm{TC}$ MIBI). SK, KU, NT, and SS contributed to the conception of the study and its design. All authors read and approved the final manuscript.

\section{Acknowledgements}

The authors are grateful to Hideki Matsumoto, Ph.D., who kindly gifted us the cell line. The authors thank Mahub e Kohda, M.D., Ph.D., Koshi Ikeda, M. D., Ph.D., Atsushi Komemushi, M.D., Ph.D., and Yoko Harima, M.D., Ph.D., for the helpful discussions and participation in the interpretation of immunocytochemistry data, in vitro and in vivo data. The authors deeply thank Audrius Stundzia, Ph.D., for his invaluable help with the proofreading.

Received: 22 November 2014 Accepted: 24 February 2015

Published online: 17 March 2015

\section{References}

1. Dempke WC, Suto T, Reck M. Targeted therapies for non-small cell lung cancer. Lung Cancer. 2010;67:257-74.

2. Perez-Tomas R. Multidrug resistance: retrospect and prospects in anti-cancer drug treatment. Curr Med Chem. 2006;13:1859-76.

3. Kibria G, Hatakeyama H, Harashima H. Cancer multidrug resistance: mechanisms involved and strategies for circumvention using a drug delivery system. Arch Pharm Res. 2014;37:4-15.

4. Kim YH, Ishii G, Goto K, Ota S, Kubota K, Murata Y, et al. Expression of breast cancer resistance protein is associated with a poor clinical outcome in patients with small-cell lung cancer. Lung Cancer. 2009;65:105-11.

5. Moretti $\mathrm{JL}$, Hauet N, Caglar M, Rebillard O, Burak Z. To use MIBI or not to use MIBI? That is the question when assessing tumour cells. Eur J Nucl Med Mol Imaging. 2005:32:836-42.

6. Benderra Z, Faussat AM, Sayada L, Perrot JY, Tang R, Chaoui D, et al. Factors in adult acute myeloid leukemia. Clin Cancer Res. 2005;11:7764-72.

7. Zhou D-C, Simonin G, Faussat A-M, Zittoun R, Marie J-P. Effect of the multidrug inhibitor GG918 on drug sensitivity of human leukemic cells. Leukemia. 1997;11:1516-22.
8. Pennock GD, Dalton WS, Roeske WR, Appleton CP, Mosley K, Plezia P, et al. Systemic toxic effects associated with high-dose verapamil infusion and chemotherapy administration. J Natl Cancer Inst. 1991;83:105-10.

9. Erlichman C, Moore M, Thiessen J, Kerr IG, Walker S, Goodman P, et al. Phase I pharmacokinetic study of combined with doxorubicin. Cancer Res. 1993:53:4837-42.

10. Utsunomiya K, Ballinger JR, Piquette-Miller M, Rauth AM, Tang W, Su ZF, et al. Comparison of the accumulation and efflux kinetics of technetium-99 m sestamibi and technetium-99 $\mathrm{m}$ tetrofosmin in an MRP-expressing tumour cell line. Eur J Nucl Med. 2000;27:1786-92.

11. Ballinger JR, Hua HA, Berry BW, Firby P, Boxen I. Technetium-99 m-sestamibi as an agent for imaging P-glycoprotein-mediated multi-drug resistance: in vitro and in vivo studies in a rat breast tumour cell line and its doxorubicin-resistant variant. Nucl Med Commun. 1995;16:253-7.

12. Tatsumi M, Tsuruo T, Nishimura T. Evaluation of MS-209, a novel multidrugresistance-reversing agent, in tumour-bearing mice by technetium-99 m-MIBI imaging. Eur J Nucl Med. 2002;29:288-4.

13. Takahashi A, Yano T, Matsumoto H, Ohnishi K, Ishioka N, Ohnishi T. Apoptosis induced by high-LET radiation is not affected by cellular p53 gene status. Int J Radiat Biol. 2005;81:581-6.

14. Iwasaki T, Mukai M, Tsujimura T, Tatsuta M, Nakamura H, Terada N, et al. Ipriflavone inhibits osteolytic bone metastasis of human breast cancer cells in a nude mouse model. Int J Cancer. 2002;100:381-7.

15. Vanhoefer U, Cao S, Minderman H, Tóth K, Scheper RJ, Slovak ML, et al. PAK-104P, a pyridine analogue, reverses paclitaxel and doxorubicin resistance in cell lines and nude mice bearing xenografts that overexpress the multidrug resistance protein. Clin Cancer Res. 1996;2:369-77.

16. Allred DC, Harvey JM, Berardo M, Clark GM. Prognostic and predictive factors in breast cancer by immunohistochemical analysis. Mod Pathol. 1998;11:155-68.

17. Hyafil F, Vergely C, Du Vignaud P, Grand-Perret T. In vitro and in vivo reversal of multidrug resistance by GF120918, an acridone carboxamide derivative. Cancer Res. 1993;53:4595-602.

18. Shareef MM, Brown B, Shajahan S, Sathishkumar S, Arnold SM, Mohiuddin M, et al. Lack of P-glycoprotein expression by low-dose fractionated radiation results from loss of nuclear factor-KB and NF-Y activation in oral carcinoma cells. Mol Cancer Res. 2008;6:89-98.

19. Gupta S, Koru-Sengul T, Arnold SM, Devi GR, Mohiuddin M, Ahmed MM. Low-dose fractionated radiation potentiates the effects of cisplatin independent of the hyper-radiation sensitivity in human lung cancer cells. Mol Cancer Ther. 2011;10:292-302.

20. Leslie EM, Deeley RG, Cole SP. Multidrug resistance proteins: role of P-glycoprotein, MRP1, MRP2, and BCRP (ABCG2) in tissue defense. Toxicol Appl Pharmacol. 2005;204:216-37.

21. Del Vecchio S, Salvatore M. $99 \mathrm{mTC}-\mathrm{MIBI}$ in the evaluation of breast cancer biology. Eur J Nucl Med Mol Imaging. 2004;31:S88-96.

22. Mohan HK, Miles KA. Cost-effectiveness of $99 \mathrm{mTc}$-sestamibi in predicting response to chemotherapy in patients with lung cancer: systematic review and meta-analysis. J Nucl Med. 2009;50:377-81.

23. Kao CH, Hsieh JF, Tsai SC, Ho YJ, Lee JK. Quickly predicting chemotherapy response to paclitaxel-based therapy in non-small cell lung cancer by early technetium-99 m methoxyisobutylisonitrile chest single-photon-emission computed tomography. Clin Cancer Res. 2000;6:820-4.

24. Dirlik A, Burak Z, Goksel T, Erinc R, Karakus H, Ozcan Z, et al. The role of Tc-99 $\mathrm{m}$ sestamibi imaging in predicting clinical response to chemotherapy in lung cancer. Ann Nucl Med. 2002;16:103-8.

25. Ozols RF, Cunnion RE, Klecker RW, Hamilton TC, Ostchega Y, Parrillo JE, et al. Verapamil and adriamycin in the treatment of drug-resistant ovarian cancer patients. J Clin Oncol. 1987;5:641-7.

26. Mistry P, Stewart AJ, Dangerfield W, Okiji S, Liddle C, Bootle D, et al. In vitro and in vivo reversal of $\mathrm{P}$-glycoprotein-mediated multidrug resistance by a novel potent modulator, XR9576. Cancer Res. 2001;61:749-58. 